Supporting Information

\title{
Structures and Sorption Properties of lonic Crystals of Macrocation-Dawson-type Polyoxometalates with Different Charges
}

Sayaka Uchida, Ryosuke Kawamoto, Takeo Akatsuka, Shiro Hikichi, and Noritaka Mizuno*

Department of Applied Chemistry, School of Enginnering, The University of Tokyo,

7-3-1 Hongo, Bunkyo-ku, Tokyo 113-8656 Japan 


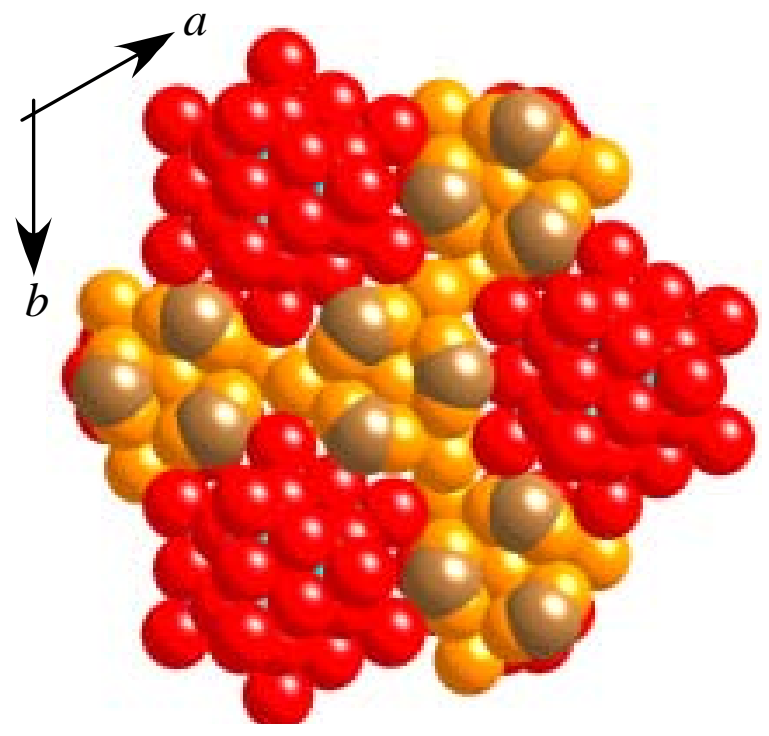

Figure S-1. Space filling model showing the arrangements of constituent ions in $a b$-plane of $\mathbf{1 b}$. Red, orange, and brown show the oxygen of the polyoxometalate, oxygen of the macrocation, and carbon, respectively. 

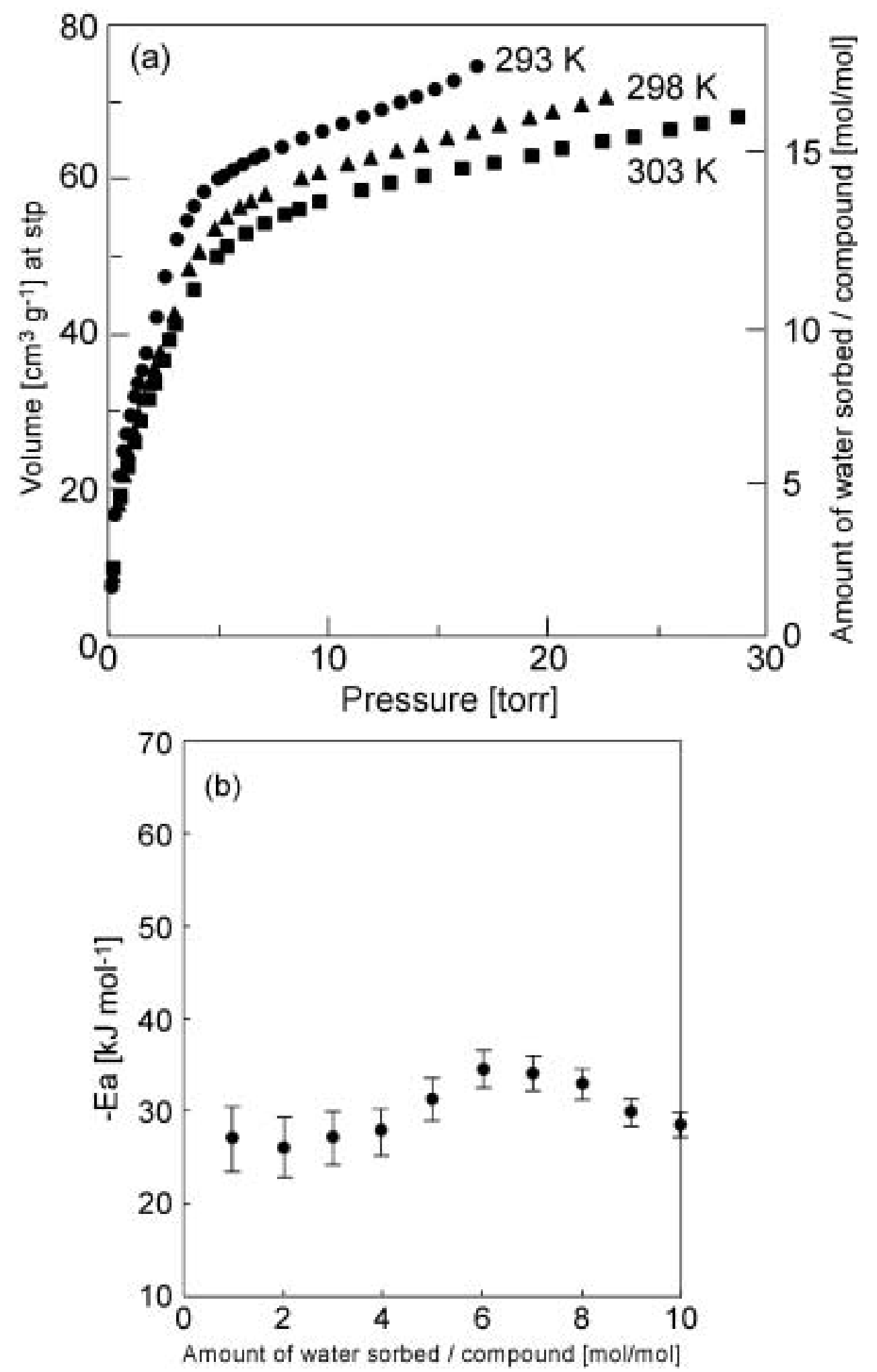

Figure S-2 (a) Water sorption isotherms of $\mathbf{1 b}$ at $293 \mathrm{~K}$ (circle), $298 \mathrm{~K}$ (triangle), and $303 \mathrm{~K}$ (square).

(b) Calculated water sorption energy of $\mathbf{1 b}$ using the Clausius-Clapeyron's equation. 

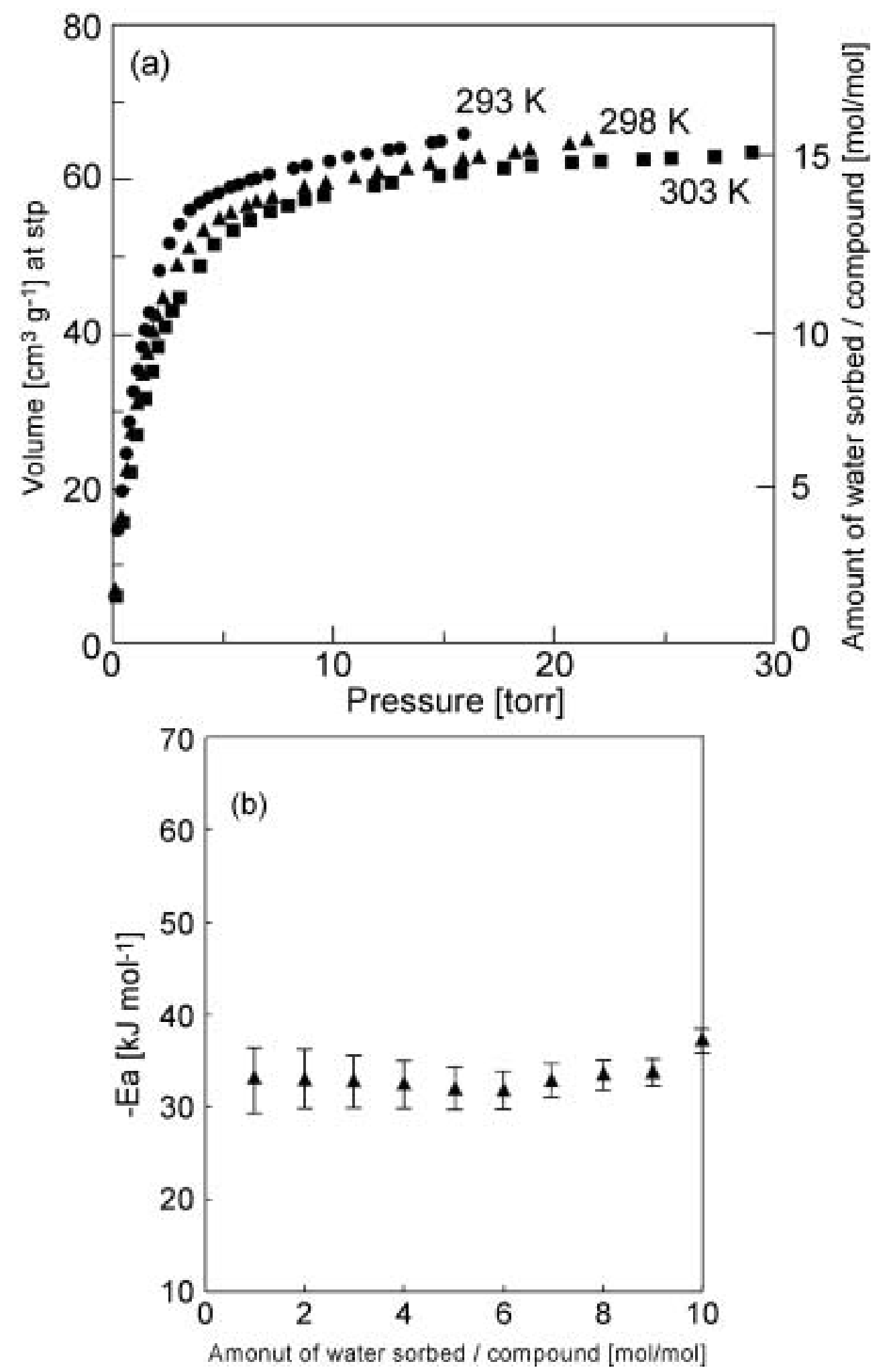

Figure S-3 (a) Water sorption isotherms of $\mathbf{2 b}$ at $293 \mathrm{~K}$ (circle), $298 \mathrm{~K}$ (triangle), and $303 \mathrm{~K}$ (square).

(b) Calculated water sorption energy of $\mathbf{2 b}$ using the Clausius-Clapeyron's equation. 

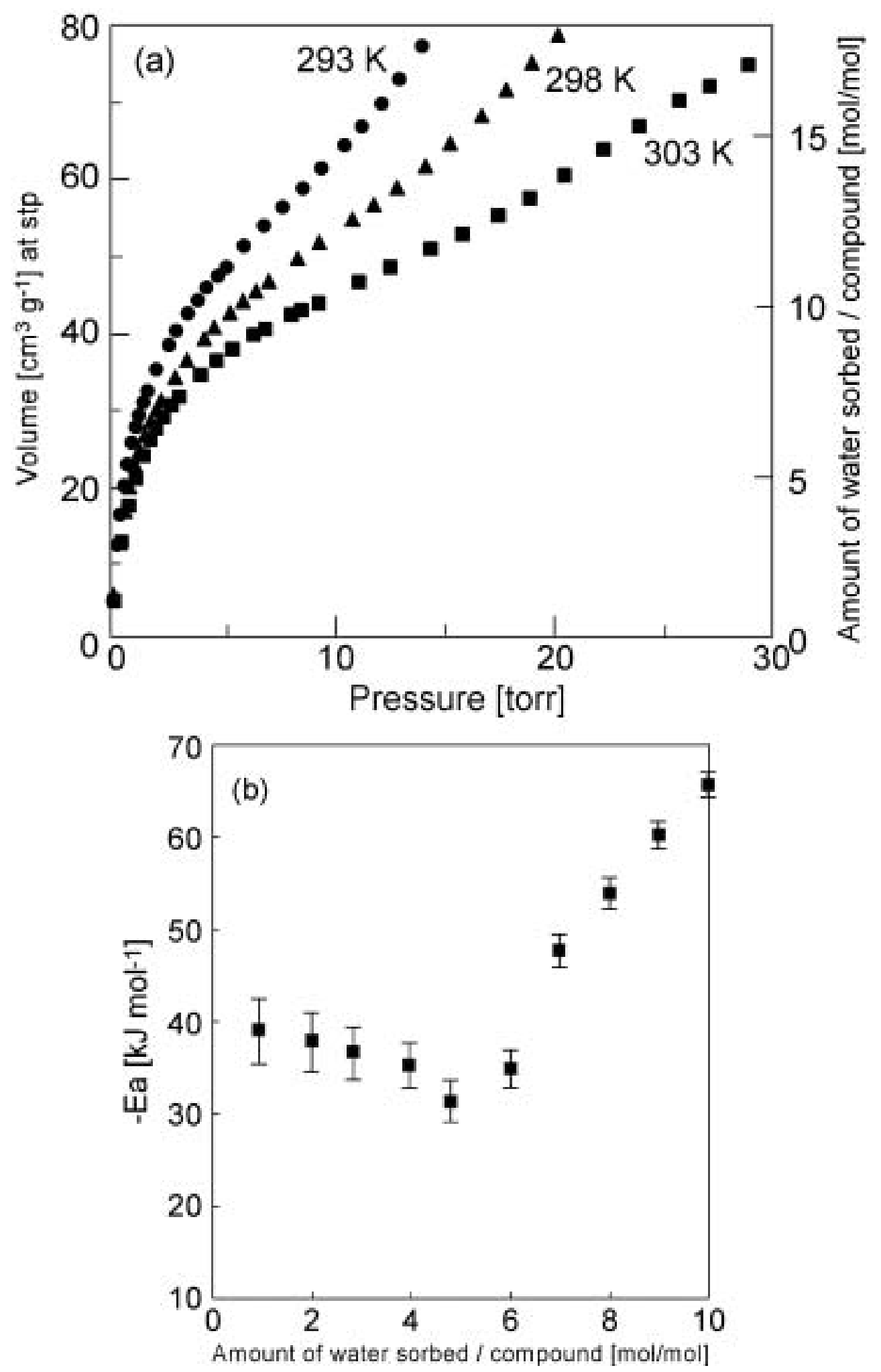

Figure S-4 (a) Water sorption isotherms of $\mathbf{3 b}$ at $293 \mathrm{~K}$ (circle), $298 \mathrm{~K}$ (triangle), and $303 \mathrm{~K}$ (square).

(b) Calculated water sorption energy of $\mathbf{3 b}$ using the Clausius-Clapeyron's equation. 